\title{
Remodulation of the tumor microenvironment by regulatory $T$ cells
}

\author{
Chang Liu ${ }^{1 *}$, Maria Chikina ${ }^{2}$, Creg J Workman³ ${ }^{3}$ Dario AA Vignali ${ }^{3}$ \\ From 30th Annual Meeting and Associated Programs of the Society for Immunotherapy of Cancer (SITC 2015) \\ National Harbor, MD, USA. 4-8 November 2015
}

The tumor microenvironment is a complex system, which is composed of various types of non-tumor cells including stromal fibroblasts, the blood and lymphatic vascular networks, the extracellular matrix and notably, the infiltrating immune cells. Regulatory $\mathrm{T}$ cells $\left(\mathrm{T}_{\text {reg }}\right.$ cells) play a pivotal role in tumor malignant progression and contribute to the resistance of tumors to traditional anti-cancer therapies; however, the elimination of $\mathrm{T}_{\text {reg }}$ cells is not a clinically viable approach, given their crucial role in maintaining immune homeostasis and preventing autoimmunity. Our laboratory has recently reported that $\mathrm{T}_{\text {reg-restricted genetic disruption of Neu- }}$ ropilin-1 (Nrp1) selectively induced destabilization of $\mathrm{T}_{\text {reg }}$ cells within the tumor microenvironment, leading to tumor clearance without inducing autoimmunity. Interestingly, despite of their dramatic tumor-suppressive function, Nrp1-deficient $\mathrm{T}_{\text {reg }}$ cells are present in tumor in a comparable manner (number and kinetics) to their wild type counterparts, which provides an invaluable research tool to interrogate the function of intratumoral $\mathrm{T}_{\text {reg }}$ cells without physically removing them and inducing systemic autoimmunity. In this study we aim to systematically investigate the cellular and molecular mediators as well as the underlying mechanisms of $\mathrm{T}_{\mathrm{reg}}$-cell function within the tumor microenvironment using a systems biology approach. With the

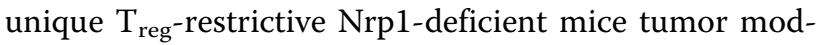
els combined with a multifaceted approach that consists of flow cytometry based immunophenotyping and largescale transcriptomic profiling, our results indicated that $\mathrm{T}_{\text {reg }}$ cells act as an early key regulator of tumor immune infiltration and actively induce the global remodulation of the tumor immune transcriptome. Computational deconvolution analysis of the gene profiling data derived from mixed populations further predicted a list of

${ }^{1}$ Department of Immunology, University of Pittsburgh, Pittsburgh, PA, USA Full list of author information is available at the end of the article critically modified targets that are regulated at the single cell level. The functional validation of these targets may provide mechanism(s) by which $\mathrm{T}_{\text {reg }}$ cells interplay with the tumor microenvironment to potentiate tumor growth. This may lead to the development of novel and selective cancer immunotherapies.

\section{Authors' details}

${ }^{1}$ Department of Immunology, University of Pittsburgh, Pittsburgh, PA, USA. ${ }^{2}$ Computational and Systems Biology, University of Pittsburgh, Pittsburgh, PA, USA. ${ }^{3}$ University of Pittsburgh, Pittsburgh, PA, USA.

Published: 4 November 2015

doi:10.1186/2051-1426-3-S2-P409

Cite this article as: Liu et al:: Remodulation of the tumor

microenvironment by regulatory T cells. Journal for ImmunoTherapy of Cancer 2015 3(Suppl 2):P409.

Submit your next manuscript to BioMed Central and take full advantage of:

- Convenient online submission

- Thorough peer review

- No space constraints or color figure charges

- Immediate publication on acceptance

- Inclusion in PubMed, CAS, Scopus and Google Scholar

- Research which is freely available for redistribution 